\title{
Global Surgical Care in the UN Post-2015 Sustainable Development Agenda
}

\author{
Jaymie Ang Henry ${ }^{1,2} \cdot$ Fizan Abdullah ${ }^{3,4}$
}

Published online: 19 October 2015

(C) Société Internationale de Chirurgie 2015

\section{Introduction}

The 2015 Millennium Development Goals (MDGs) provided the global development community with an opportunity to reflect on the triumphs and challenges encountered over the last 15 years. Despite great strides in achieving maternal and child health targets, significant disparities in maternal surgical care persist [1]. Investments and scale-up of obstetric surgery and anaesthesia care are critical to close the gap in maternal mortality [2]. These and other essential surgical interventions address inequalities in health that remain outside the defined scope of the international global health agenda.

Although the international community fell short of prioritizing surgical care as part of the MDGs, the post-2015 sustainable development agenda represented a rare opportunity for surgical care to be recognized as a global priority. As part of this multi-year agenda setting process, governments and members of civil society have been coming together through a number of processes to develop a core list of goals, targets, and indicators to guide

Fizan Abdullah

fabdullah@luriechildrens.org

1 The Global Alliance for Surgical, Obstetric, Trauma, and Anaesthesia Care (The G4 Alliance), 101 Avenue of the Americas, Suite 908, New York, NY 10013, USA

2 Department of Surgery, The University of Chicago, A27 S Maryland Ave, Chicago, IL 60637, USA

3 Department of Surgery, Feinberg School of Medicine, Northwestern University, 251 East Huron St., Galter 3-150, Chicago, IL 60611-2950, USA

4 Division of Pediatric Surgery, Ann and Robert H. Lurie Children's Hospital of Chicago, Northwestern University, 225 E. Chicago Ave, Box 63, Chicago, IL 60611, USA development around the world (Fig. 1). Despite efforts to raise the profile of surgical care as a critical public health issue, it has remained conspicuously absent from post-2015 discussions [3]. This critical omission deserves further examination, and warrants the mobilization of stakeholders in surgical care and anaesthesia from around the world to unite in support of the neglected surgical patient.

\section{A global crisis}

The 2010 Global Burden of Disease Report illustrates the extent of the health burden caused by the lack of access to essential surgical interventions. Lack of basic surgical care, encompassing obstetrics, anaesthesia, and trauma care, contributes to 11-15\% of the burden of disease [4], affects 1 in 7 marginalized persons in the world, intersects with all known disease categories, and results in catastrophic economic, moral, and social consequences as well as placing an immense burden on health systems. These disparities have far-reaching impact, affecting millions worldwide across all socioeconomic and demographic strata.

Essential surgical care addresses surgical diseases that are largely neglected; including obstetric surgical care, congenital diseases, advanced tumours, cataracts, hernias, and basic surgical care for injuries, emergencies, and consequences of infectious diseases. These conditions continue to represent a public health challenge that disproportionately impacts the most marginalized individuals in society, with the greatest impact on women, children, and vulnerable populations.

Recent estimates account for up to 5 billion people who need some form of surgical care but have little to no access to this technology that is freely available in much of the developed world [5]. The global burden of non- 


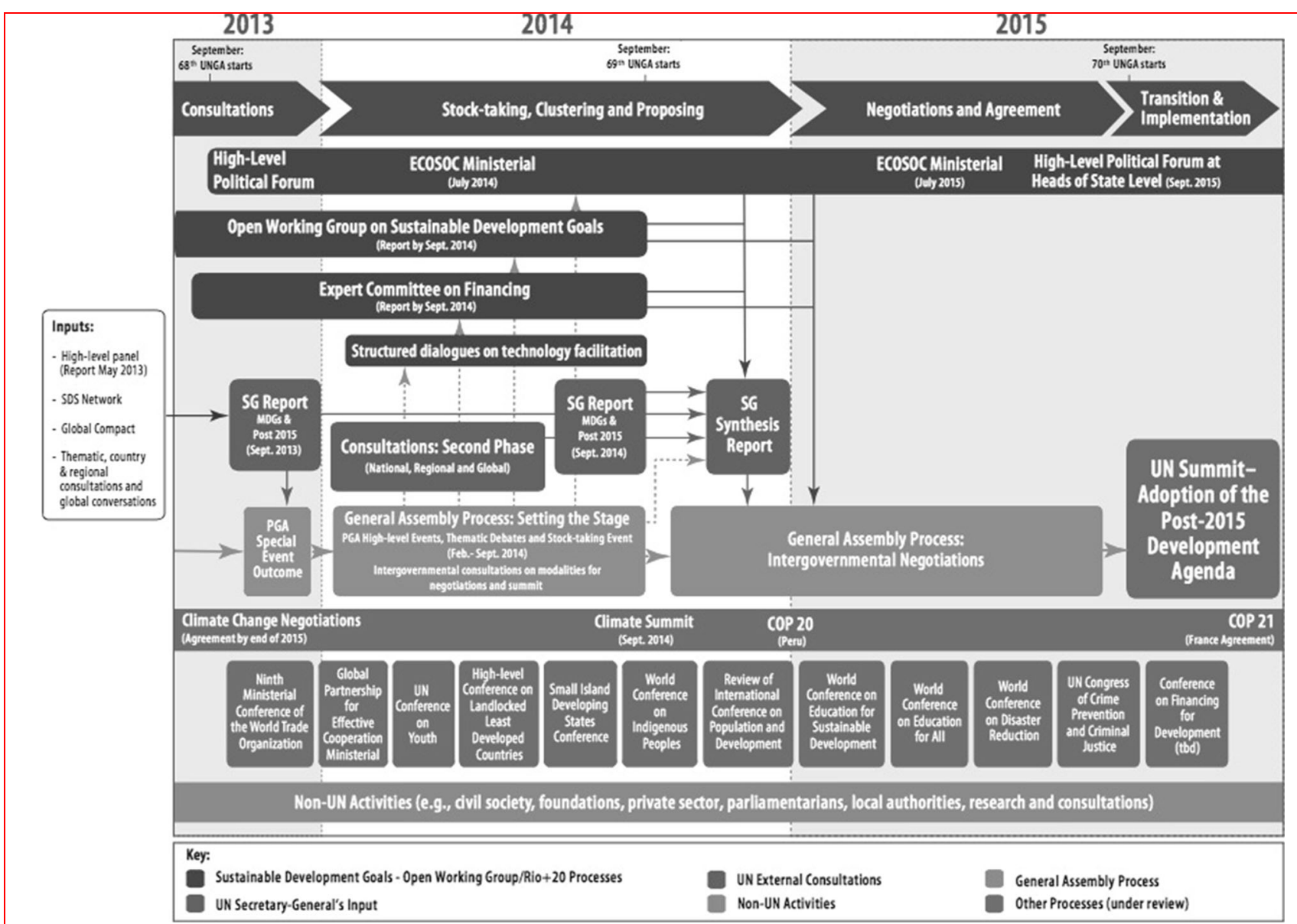

Fig. 1 Processes Feeding into Post-2015 Sustainable Development Agenda. Source United Nations Foundation and Dalberg analysis

communicable diseases, which frequently requires surgical intervention, has overtaken that of infectious diseases; with conditions such as cancer, heart disease, and diabetes increasing dramatically in less-developed countries [6]. Although international priorities are starting to reflect the importance of non-communicable diseases, provision of essential services lags behind, with continued focus on provision of care for infectious diseases and preventive strategies. Lack of access to safe and timely surgical care results in more deaths and disability than HIV/AIDS or malaria and deserves similar attention and action to address deficiencies and improve care [7].

The links between newborn and maternal survival and access to quality surgery are clear. It is estimated that one in three pregnant women will require a medical or surgical intervention during birth and between 5 and $15 \%$ will require a caesarean section [8]. Deaths from road traffic accidents increased by $32 \%$ between 1990 and 2010 [9]. Reducing deaths and disabilities from any of these causes requires that effective emergency and essential surgical care services be integrated into the public health system.
Africa, with a population of 1.1 billion, has $1 \%$ the number of surgeons practicing as in the US, with its population of 314 million [10]. In high-income countries, there are more than 14 operating rooms per 100,000 population compared with an average of one operating room per 100,000 population in sub-Saharan Africa [11]. Pulse oximeters, essential equipment to ensure safe surgery and a necessary component of operating rooms, are lacking in as many as 77,000 operating rooms globally. This amounts to more than 30 million operations worldwide without basic safe monitoring [5]. Lack of access to essential medical and surgical instruments as well as inadequate sterilization and infection control capacity leads to a post-operative infection rate that reaches up to $45 \%$ in some low-resource countries [12]. Evidence suggests that there are 15 basic surgical interventions that provide coverage for approximately $80 \%$ of basic surgical need, particularly in rural areas where doctors are scarce [13]. Ensuring universal access to cost-effective, safe, and high-quality surgical care and anaesthesia will require the long-term support of a coordinated global effort. 


\section{Essential surgery and sustainable development}

Diseases requiring surgical care place an immense burden on health care systems, diverting resources from other priorities. Women, children, and people in their economically productive years are particularly impacted by this lack of surgical access. Congenital deformities such as clubfoot, cleft palate, and hernia are commonly left untreated. The global financial cost of childhood blindness based on loss of future earning capacity is US\$6-27B [14]. Injuries from obstructed and complicated labours kill and injure both mother and child. Women are further impacted as they, typically, become primary caregivers for family members who are injured and disabled. Road traffic injuries, accounting for about $30-86 \%$ of surgical admissions in low- and middle-income countries (LMICs) [15], weaken economic growth with costs borne disproportionately by the poor. It is estimated that the annual cost of road traffic injuries is US\$500B [16]. There is a devastating impact on education with hundreds of thousands of schoolage children in LMICs losing their right to an education every year due to road traffic injury [17]. Strengthening essential surgical services addresses these neglected surgical diseases, strengthens the overall health system, and directly contributes to sustainable development. Investments in service delivery, local skilled workforce, infrastructure, local health governance, and improved financial support ensures the health of nations, protects individuals from falling into extreme poverty from lack of access to basic surgical services and high out of pocket costs, and protects vulnerable societies from sudden outbreaks of infectious diseases or unforeseen calamities.

The United Nations' recent report on behalf of the HighLevel Panel of Eminent Persons on the Post-2015 Development Agenda stated that for every $\$ 1$ spent on strengthening local surgical capacity, $\$ 10$ was generated through enhanced health and increased productivity [18]. Further research has shown that the benefit to cost ratio for expanding surgical capacity at first-referral centres such as district hospitals was as high as 10:1 [19]. Strengthening surgical access, capacity, and quality is a sound investment. Surgical care is increasingly recognized as a highly cost-effective strategy for strengthening health systems in low-resource settings [20] with treatment of most surgical conditions requiring basic surgical procedures and equipment [21].

\section{Global surgery stakeholder engagement}

As the world shifts its focus towards a new post-2015 sustainable framework to guide global development goals and priorities for the next 15 years, it is critical that access to safe, essential, surgical care and anaesthesia are prioritized as part of the global development agenda. In response to this need, a group of 29 international organizations, representing over 2 million members from over 140 countries, have been coordinating and engaging in global surgery advocacy efforts. The group launched an inaugural side event during the World Health Assembly in May 2014, bringing together a global panel of speakers and advocates including Ambassador Jimmy Kolker, Assistant Secretary for Global Affairs with the US Health and Human Service Office of Global Affairs, and leadership from the International College of Surgeons, the World Federation of Societies of Anaesthesiologists, and the International Federation of Medical Students Associations.

In June and July of 2014, the Global Surgery and Anaesthesia stakeholders contributed language to official statements delivered during the proceedings of the United Nations (UN) General Assembly's Open Working Group on sustainable development goals (SDGs). The group engaged in UN open consultations and engaged with UN Major Groups, collaborating on the development of statements delivered to the UN Secretary General and General Assembly. In August 2014, the group presented a stakeholder statement at the UN department of public information (DPI)/non-governmental organization (NGO) Conference; an annual meeting that attracts over 900 NGOs and more than 4000 participants. Subsequently, this group has worked together on a number of advocacy initiatives to raise awareness and build political priority for surgical care, including hosting an official UN side event in March of 2015 on the role of surgical care as an essential health service as part of universal health coverage (UHC) and the post-2015 SDGs.

Throughout these efforts, the group, which has become the G4 Alliance [22], has focused on developing a strong case for the social and economic importance of integrating surgical care and anaesthesia as part of the post-2015 SDGs, and supporting the development of clear indicators and metrics to prioritize surgical care and track progress. The Global Alliance for Surgical, Obstetric, Trauma, and Anaesthesia Care, the G4 Alliance, is a network of 52 major surgical, obstetric, trauma, and anaesthesia organizations dedicated to building priority for the neglected surgical patient.

\section{A post-2015 goal}

The UN post-2015 sustainable development goal (SDG) has potential for surgical care and anaesthesia to be situated within goal 3: ensure healthy lives and promote well-being for all at all ages, which contains target 3.8: achieve universal health coverage, including financial risk protection, access to quality essential health care services and access to 
safe, effective, quality, and affordable essential medicines and vaccines for all. This aligns well with the recent WHO landmark resolution on surgical care on 'strengthening emergency and essential surgical care and anaesthesia as a component of Universal Health Coverage' [23]. This target should be cross-referenced with other goals such as ending poverty (SDG 1) and achieving gender equality through access to essential reproductive health services (SDG 5) [24]. Continued advocacy at the country level is critical to solidify political priority for surgical care and anaesthesia.

\section{Growing momentum for strengthening global surgical care}

The importance of surgical care as part of health systems strengthening and UHC is gaining significant global support. During the 67th World Health Assembly in May 2014, support was recorded from over 30 countries at an event hosted by Zambia, Nigeria, USA, Rwanda, Kenya, Senegal, Australia, and the United Kingdom of Great Britain and Northern Ireland. On 29 January 2015, the World Health Organization (WHO) Executive Board unanimously adopted a draft resolution on strengthening surgical care and anaesthesia as a component of UHC [23], In May 2015; the draft resolution received full support and was formally ratified. Furthermore, the World Bank, the WHO, and USAID responded to a collective appeal from over 120 global surgery, obstetric, trauma, and anaesthesia partners in a campaign hosted by the G4 Alliance, prioritizing surgical indicators as part of the 'Global Reference List of 100 Core Health Indicators' [25]. Dr. Jim Yong Kim, President of the World Bank, acknowledged the importance of Essential Surgery [26]. The sustainable development solutions network (SDSN), a branch of the United Nations directly involved in the post-2015 process, has endorsed an indicator for the availability of surgical care under Goal 5 [27]. The Government of Tanzania has proposed increasing access to essential surgery as a target in the post-2015 SDG agenda at a UN side event held in conjunction with the OWG discussions [28]. The Government of the United Kingdom of Great Britain and Ireland voiced their support for the inclusion of surgery as an essential health service within Universal Health Coverage in a recent debate at the House of Lords [29].

\section{Next steps: the need for indicators to track success}

Clearly, there is growing support for the inclusion of surgical care as part of the basic package of health care and as a priority issue on the global development agenda. To ensure these advocacy efforts contribute to measurable progress, it will be critical for the global surgical community to come together to identify a series of well-defined and easily measurable indicators to help guide policy makers, both at the national level and within multilateral organizations such as the WHO and the UN. The Lancet Commission on Global Surgery has proposed several metrics to track progress in global surgical care. In order to put in place a Global Accountability Framework that drives country action, however, there is a political process that follows the scientific effort that takes into account country-level buy in and support.

\section{Conclusion}

The sustainable provision of safe surgical and anaesthesia care is critical and essential for integrated health care systems and will decrease mortality and morbidity from surgical diseases which are neglected in too many settings. In turn, access to such care reduces economic and social disparities, and prevents disability, deformity, and other adverse health outcomes arising from injuries and noncommunicable diseases. Surgical care should be made accessible to all nations and all people, regardless of economic, geographic, cultural, and regional differences. Strengthening essential surgical care as a post-2015 development goal represents a profound shift in strategies addressing the burden of disease and heralds an era of transformational change in health.

\section{Compliance with ethical standards}

Conflict of interest We declare that we have no potential conflicts of interest.

\section{References}

1. Countdown Report Writing Group (2012) Building a future for women and children. Lancet 379(9832):2121-2122. http://www. thelancet.com/journals/lancet/article/PIIS0140-6736(12)60914-3/ fulltext

2. Dare AJ, Gillies R, Greenberg SL, Wilson IH (2014) Investing in obstetric surgery and anaesthesia to close the gap in maternal mortality. Lancet 383(9931):1803-1804

3. Nations U (2014) Outcome Document of the Open Working Group on the post-2015 agenda. http://www.thelancet.com/jour nals/lancet/article/PIIS0140-6736(14)60876-X/fulltext

4. Murray CJ, Vos T, Lozano R, Naghavi M, Flaxman AD, Michaud C et al (2012) Disability-adjusted life years (DALYs) for 291 diseases and injuries in 21 regions, 1990-2010: a systematic analysis for the Global Burden of Disease Study 2010. Lancet 380(9859):2197-2223

5. Meara JG, Leather AJ, Hagander L, Alkire BC, Alonso N, Ameh EA et al (2015) Global Surgery 2030: evidence and solutions for achieving health, welfare, and economic development. Lancet. doi:10.1016/S0140-6736(15)60160-X

6. Lozano R, Naghavi M, Foreman K, Lim S, Shibuya K, Aboyans $\mathrm{V}$ et al (2012) Global and regional mortality from 235 causes of 
death for 20 age groups in 1990 and 2010: a systematic analysis for the Global Burden of Disease Study 2010. Lancet 380 (9859):2095-2128

7. World Health Organization (2006) Opportunities for Africa's newborns: Practical data, policy and programmatic support for newborn care in Africa. p 68. http://www.who.int/pmnch/media/ publications/aonsectionIII_3.pdf

8. McQueen et al (2010) Essential surgery: integral to the right to health. Health Hum Rights 12(1):137-152

9. Weiser TG, Regenbogen SE, Thompson KD, Haynes AB, Lipsitz SR, Berry WR et al (2008) An estimation of the global volume of surgery: a modelling strategy based on available data. Lancet 372(9633):139-144

10. Nehjad SB, Allegranzi B, Syed SB, Ellis B, Pittet D (2011) Healthcare associate infection in Africa: a systematic review. Bull World Health Organ 89:757-765. doi:10.2471/BLT.11.08817

11. Watters DA, Bayley AC (1987) Training doctors and surgeons to meet the surgical needs of Africa. Br Med J 295(6601):761-763

12. Smith AF, Smith JG (1996) The economic burden of global blindness: a price too high! Br J Ophthalmol 80(4):276-277

13. Odero W, Garner P, Zwi A (1997) Road traffic injuries in developing countries: a comprehensive review of epidemiological studies. Trop Med Int Health 2(5):445-460

14. Gosselin RA, Spiegel DA, Coughlin R, Zirkle LG (2009) Injuries: the neglected burden in developing countries. Bull World Health Organ 87(4):246a

15. Policy briefing, Road traffic injury and the Post-2015 development agenda. http://sustainabledevelopment.un.org/content/docu ments/8946Transport\%20Health\%20Policy\%20Brief\%20.pdf

16. A New Global Partnership: Eradicate Poverty and transform Economies through sustainable Development: The Report of the High-Level Panel of eminent Persons on the Post-2015 Development Agenda (2013). United Nations Publication

17. Jamison D, Jha P, Bloom D (2008) The Challenge of Diseases. Copenhagen Consensus 2008 Challenge Paper

18. Bickler S, Spiegel D (2010) Improving surgical care in low- and middle-income countries: a pivotal role for the world health organization. World J Surg 34:386-390. doi: 10.1007/s00268009-0273-2. http://www.ncbi.nlm.nih.gov/pmc/articles/PMC281 6819/pdf/268_2009_Article_273.pdf

19. Grimes CE, Henry JA, Maraka J, Mkandawire NC, Cotton M (2014) Cost-effectiveness of surgery in low- and middle-income countries: a systematic review. World J Surg 38(1):252-263. doi:10.1007/s00268-013-2243-y

20. Chao TE, Sharma K, Mandigo M, Hagander L, Resch SC, Weiser TG et al (2014) Cost-effectiveness of surgery and its policy implications for global health: a systematic review and analysis. Lancet Glob Health 2(6):e334-e345

21. McIntyre T, Zenilman M (2010) Globalization of surgery: let's get serious. Arch Surg 145(8):715-716. http://archsurg.jamanet work.com/article. aspx ?articleid $=406139$

22. Alliance $G$ (2015) The global alliance for surgical, obstetric, trauma, and anaesthesia care. www.theg4alliance.org. Accessed 30 Aug 2015

23. World Health Organization, strengthening emergency and essential surgical care and anaesthesia as a component of universal health coverage EB135/3 (16 May 2014). http://apps.who. int/gb/ebwha/pdf_files/EB135/B135_3-en.pdf

24. United Nations General Assembly. Report of the open working group of the general assembly on sustainable development goals. A/68/97 (12 Aug 2014). http://www.un.org/ga/search/view_doc. asp?symbol $=\mathrm{A} / 68 / 970$

25. World Health Organization. Global reference list of 100 core health indicators. Working Version 5. Geneva (17 Nov 2014). http://www.internationalhealthpartnership.net/fileadmin/uploads/ ihp/Documents/Key_Issues/One_M_E_Platform/Global_RefList_ Core_Indicators_V5_17Nov2014_WithoutAnnexes.pdf

26. The Lancet Commission on Global Surgery, Video address, Jim Yong Kim, (17 Jan 2014). http://www.thelancet.com/commis sions/global-surgery

27. Indicators for sustainable development goals: a report by the leadership council of the sustainable development solutions network. http://unsdsn.org/wp-content/uploads/2014/05/140522-SDSNIndicator-Report.pdf

28. Permanent mission of the United Republic of Tanzania to the United Nations, Official Statement, 8th Open Working Group on Sustainable Development Goals side event (6 Feb 2014). http:// essentialsurgery.com/wp-content/uploads/2014/02/Tanzania-Offi cial-Statement.pdf

29. Parliament of the United Kingdom, World Health Organisation Question for Short Debate (2 July 2014). http://www.publica tions.parliament.uk/pa/ld201415/ldhansrd/text/140702-0002.htm\# 14070292000137 